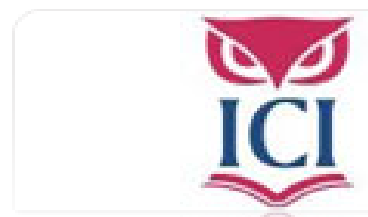

IUS. Revista del Instituto de Ciencias Jurídicas de Puebla A.C.

ISSN: 1870-2147

revista.ius@hotmail.com

Instituto de Ciencias Jurídicas de Puebla A. C.

México

Ferrajoli, Luigi

El derecho penal del enemigo y la disolución del derecho penal

IUS. Revista del Instituto de Ciencias Jurídicas de Puebla A.C., núm. 19, 2007, pp. 5-22

Instituto de Ciencias Jurídicas de Puebla A. C.

Puebla, México 


\section{EL DERECHO PENAL DEL ENEMIGO Y LA DISOLUCIÓN DEL DERECHO PENAL}

Luigi Ferrajoli*

SUMARIO

I. Dos significados de la fórmula "derecho penal del enemigo"

II. El terrorismo penal (el derecho penal como guerra, la guerra como sanción penal) III. El paradigma del enemigo y la disolución del derecho penal (derecho penal y guerra) IV. La ineficacia del derecho penal del enemigo (medios y fines penales) V. Fundamentalismo occidental (La alternativa del derecho y de la Razón)

\section{Dos significados de la fórmula "derecho penal del enemigo"}

En primer término, quiero expresar cierto desasosiego por tener que afrontar el tema de este seminario. Tal sentimiento proviene de una sensación: la producida por el hecho mismo de que una fórmula sugestiva, quizá provocadora y a mi juicio escandalosa, como "el derecho pena del enemigo" haya sido puesta en circulación por un jurista prestigioso; que sobre ella se realicen congresos (dos, sólo en Italia en este mes); y que en torno a la misma esté creciendo, como inevitablemente sucede en la comunidad de los juristas, una rica literatura. ${ }^{1}$ Se trata de circunstancias que bastan

\footnotetext{
* Ponencia presentada en el seminario Verso un diritto penale del nemico?, organizado por Magistratura Democratica en Roma, los días 24-25 de marzo de 2006. En curso de publicación en Questione Giustizia 2/2006. Este artículo fue publicado en Jueces para la Democracia (noviembre de 2006), en traducción de Perfecto Andrés lbáñez, a quienes agradecemos permitirnos publicarlo en México.

${ }^{1}$ La tesis de una diferenciación del derecho penal, a través de la institución de un "derecho penal del enemigo", ha sido promovida por Günter Jakobs, Derecho penal del ciudadano y derecho penal del enemigo, en G. Jakobs y M. Cancio Meliá, Derecho penal del enemigo, Civitas, Madrid, 2002, pp. 19-56; G. JAKоBS, "Terroristen als Personen im Recht?", en Zeitschrift für die gesamte Strafrechtswissencchaft, 4, 2005, pp. 117-134; 1d., Diritto penale del nemico? Una analisi sulle condizi della giuridicità, ponencia para el seminario celebrado en Trento los días 10-11 de marzo de 2006, sobre "Delitto politico
} 
para otorgar a la misma una ciudadanía teórica, para que, de algún modo, resulte tomada en serio y para dotarla de una apariencia de legitimidad.

He apreciado mucho las ponencias y las intervenciones producidas en este encuentro, todas informadas - pienso en la ponencia de Morosini y en las intervenciones de Spataro, D’Andria y Borracetti- en la defensa del derecho penal y de sus garantías, en alternativa a la lógica de guerra que informa el derecho penal del enemigo. Y pienso, espero, que la magistratura italiana, aunque sólo sea por su independencia y también por la experiencia adquirida en los procesos de terrorismo y de mafia, sabrá resistir a las tendencias a la desjurisdiccionalización (de-giurisdizionalizazione) del proceso de que ha hablado Francesco Palazzo. Pero ayer hemos escuchado lo que nos decía Vittorio Fanchiotti sobre la que ha llamado desprocesalización (de-processualizzazione) del tratamiento punitivo en los Estados Unidos y en Inglaterra, que ya no tiene nada de "penal" ni de "derecho". Y, por otra parte, conocemos bien la capacidad expansiva y los efectos de contagio y corrupción del imaginario penalista en una doble dirección: en relación con otros países, incluido el nuestro; en relación con los demás sectores del derecho penal -mafia, criminalidad organizada, pedofilia, tráfico de drogas - hasta incluir, en lo que va camino de ser "el imperio del miedo" exportado de los Estados Unidos a todo el planeta, los atentados contra la seguridad provenientes de la pequeña delincuencia callejera y de subsistencia. Ésta, hoy, como ha recordado Massimo Pavarini, representa en los Estados Unidos el verdadero "enemigo" contra el que se ha desencadenado una campaña de criminalización de la pobreza y de encarcelamiento masivo que ha llevado a que la población carcelaria de ese país sea en este momento de 2,500,000 personas.

Ahora es preciso preguntarse: ¿de qué estamos discutiendo cuando hablamos de "derecho penal del enemigo"?, ¿del paradigma del enemigo

e diritto penale del nemico". Como bien ha señalado M. Cancio Meliá, ¿Derecho penal del enemigo?, cit., pp. 59-102, la expresión "derecho penal del enemigo" es una contradicción en los términos, la que cabe reconocer una variante actualizada de las doctrinas penales del "tipo de autor" y del "enemigo del pueblo". Sobre el "derecho penal del enemigo" se ha formado ya una abundante literatura crítica. Al respecto, pueden verse: M. Donini, Il volto attuale dell'illecito penale. La democrazia penale tra differenziazione e sussidirietà, Giuffrè, Milano, 2004, 2.3, pp. 53-59; 1d. "ll diritto penale di fronte al “nemico'”, en Cassazione Penale, pp. 735-777; A. APONTE, Derecho penal de enemigo o derecho penal del ciudadano. Günter Jakobs y las tensiones de un derecho penal de la enemistad, Temis, Bogotá, 2005; A. Aponte, Guerra y derecho penal de enemigo. Reflexión critica sobre el eficientismo penal de enemigo, lbáñez, Bogotá, 2006; R. Zaffaroni, "Buscando al enemigo: de Satán al derecho penal cool”, trad. italiana: "Alla ricerca del nemico: da Satana al diritto penale cool”, en Studi in onore di Giorgio Marinucci, Giuffrè, Milano, 2006, ed. de E. Dolcihi y C. E. Paliero, vol. ı, pp. 757-780; F. Resta, "Nemici e criminali. Le logiche del controllo", en L'Indice penale, 1, 2006, pp. 181-227. 
en el derecho penal? Creo que hay que reconocer con absoluta firmeza que hablamos de un oxímoron, de una contradicción en los términos, que representa, de hecho, la negación del derecho penal, la disolución de su papel y de su íntima esencia, dado que la figura del enemigo pertenece a la lógica de la guerra, que es la negación del derecho, del mismo modo que éste es la negación de la guerra.

Para decirlo brevemente y haciendo uso de la expresión que da título a un bellísimo pamphlet de Raúl Zaffaroni: discutimos del derecho penal $y$ sus enemigos. ${ }^{2}$ Pues la concepción del terrorista, del delincuente como enemigo tiene aptitud bastante para arrollar todas las garantías del derecho penal, desde el principio de legalidad al de culpabilidad, desde la presunción de inocencia hasta la carga de la prueba y los derechos de la defensa.

Así las cosas, conviene distinguir dos significados, dos usos diversos de esta fórmula: a) uno primero de tipo empírico-descriptivo; descriptivo, entiéndase bien, de una perversión del derecho penal, es decir, de prácticas punitivas y represivas - pienso en las jaulas de Guantánamo o en las torturas de Abu Ghraib- que se cubren con el manto del derecho penal y son, por el contrario, su negación; y, b) otro significado, podría decirse, de tipo teórico, merced al cual "el derecho penal del enemigo" resulta presentado o recomendado como un nuevo "paradigma", un nuevo "modelo", como tal normativo, de derecho penal.

Ahora bien, en la teoría política y en la teoría jurídica no siempre -más bien casi nunca- se distingue analíticamente el diverso estatuto de los dos discursos, descriptivo en un caso, normativo en el otro. Con el resultado de que el uso descriptivo de la fórmula -más que servir de premisa de la crítica de lo que se describe sobre la base de los modelos teóricos y normativos del derecho penal elaborados por una larga y fatigosa tradición de conquistas civiles y democráticas- se transmuta, más o menos conscientemente, en un uso normativo o cuando menos en un uso en función de legitimación de lo descrito por la fórmula.

Es la falacia realista que lastra buena parte de la filosofía política y jurídica, que cambia lo que acontece por lo que, política o jurídicamente, es justo o legítimo que suceda, ocultando así su carácter ilícito y criminal. Dicho sin rodeos, se trata de la autolegitimación como derecho de las prácticas contrastantes con el modelo normativo del derecho penal, en nombre

${ }^{2}$ Zaffaroni, R., "El derecho penal y sus enemigos”, texto mecanografiado, de próxima publicación. 
de la eficiencia. Añadiré que es una falacia a menudo inconsciente. Supongo que si se pregunta a Günter Jakobs si comparte el modelo del derecho penal del enemigo, responderá que se está limitando a describir el fenómeno, destinado, sin embargo, a afirmarse al lado -o incluso a salvar- el "derecho penal del ciudadano". Por lo demás, la distinción metalingüística entre "descriptivo" y "prescriptivo" no forma parte de la cultura jurídica y política funcionalista. Recuerdo que una vez, hace veinticinco años, en el curso de un debate que tuvo lugar en Palermo, pregunté a Niklas Luhmannn si hacía un uso descriptivo o prescriptivo de su tesis según la cual el individuo es un "subsistema" del sistema social, de manera que los derechos del primero se defienden en función de la conservación del segundo. Me contestó que no entendía el sentido de la pregunta. En mucha de la cultura filosófica llamada "realista" es todavía un postulado la idea hegeliana de que "lo que es real es racional".

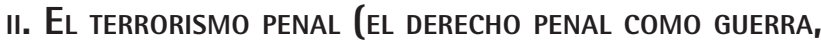 LA GUERRA COMO SANCIÓN PENAL)}

Comenzaré ahora analizando nuestra fórmula en sentido descriptivo. Como suele suceder en derecho penal nunca se inventa nada nuevo. El esquema del derecho penal del enemigo no es otra cosa que el viejo esquema del "enemigo del pueblo" de estaliniana memoria y, por otra parte, el modelo penal nazi del "tipo normativo de autor" (Tätertyp). Y enlaza con una tradición antigua y recurrente de despotismo penal inaugurada con los crimina maiestatis. Con la agravante de que aquél se ha perfeccionado mediante su abierta identificación con el esquema de la guerra, que hace del delincuente y del terrorista un enemigo a suprimir y no a juzgar.

El resultado de esta perversión es el modelo del terrorismo penal, o del derecho penal terrorista y criminal, entendido "criminal" como rasgo no de los hechos perseguidos sino del propio "derecho", a causa de las formas abiertamente terroristas que éste asume. Hemos podido escuchar lo que contaba ayer Fanchiotti sobre el Patriot Act estadunidense y sobre el modelo Guantánamo: la cancelación del habeas corpus para los ciudadanos no americanos, las privaciones de libertad por tiempo ilimitado sin acusación formal, la supresión de las garantías procesales, el establecimiento de tribunales militares especiales, la quiebra de todas las garantías en materia de interceptaciones, registros, detenciones, pruebas.

La manifestación más vergonzosa de este derecho penal criminal, como 
verdadero crimen contra la humanidad, es la tortura, que ha hecho su funesta reaparición en estos años en el tratamiento estadunidense de los llamados "enemigos combatientes" como instrumento para obtener la confesión y, al mismo tiempo, de intimidación general. Es un modelo de tortura en muchos aspectos opuesto al practicado en secreto en las cámaras de seguridad y habitualmente ocultado, negado, dejado de lado e ignorado por la opinión pública. En efecto, su aspecto más torpe es su carácter estratégico, ostensible, codificado en manuales ad hoc, ${ }^{3}$ como medio de intimidación y mortificación de las personas y de difusión del terror, con el aval incluso de ilustres penalistas. ${ }^{4}$ Sólo así se explican las espantosas fotografías de prisioneros encapuchados, con los brazos abiertos y cables eléctricos pendientes de las manos, arrastrados por el cuello con una correa, o amontonados y fotografiados desnudos y aterrorizados delante de perros azuzados, mientras ríen sus verdugos, evidentemente seguros de la impunidad, o, peor aún, de la legitimidad de sus acciones.

Es el mismo modelo de terrorismo penal, ya experimentado por las dictaduras latinoamericanas de los años sesenta y setenta ${ }^{5}$ en obsequio de la doctrina de la "seguridad nacional", y hoy practicado por los Estados Unidos con los sospechosos de terrorismo, en decenas de prisiones esparcidas por todo el mundo. Su finalidad es sembrar el terror entre todos los que, fundadamente o no, resulten sospechosos de connivencia con el terrorismo, y, al mismo tiempo, humillar al enemigo al margen del derecho

\footnotetext{
${ }^{3}$ Con el título Manuale della tortura, se ha publicado el documento de la CIA que imparte directivas sobre el trato -verdaderas y propias torturas- a que debe someterse a los prisioneros sospechosos de actividades contrarias a la "seguridad" de los Estados Unidos (Manuale della tortura. Il testo finora top-secret uscito dagli archivi USA (1963-1997), Datanews, Roma, 1999). Los mismos comandos del ejército estadunidense han reconocido la muerte de cerca de 30 personas presas en Afganistán y en lrak. Como han declarado algunos exoficiales de la CIA, entre ellos un exfuncionario de alto nivel, en una entrevista radiofónica a la Bвс el 8 de febrero de 2005, los Estados Unidos, después del 11 de septiembre de 2001, han desarrollado una actividad sistemática de secuestros ilegales de sospechosos de terrorismo, transferidos (y a veces desaparecidos) en paises del Magreb y de Oriente Medio, donde fueron sometidos a torturas en centros de detención sometidos a su control (S. Gray, "Decentramento della tortura”, en Le Monde Diplomatique, $n^{\circ}$ 4, abril, 2005, pp., 1 y 8-9). Gran parte de estas prácticas han sido declaradas ilegítimas por el Tribunal Supremo de los Estados Unidos, sin que esto haya comportado su cese efectivo. Sobre la práctica estadunidense de la tortura en el universo carcelario oculto edificado por la CIA y el Pentágono en diversos países, Cfr. G. Chiesa, La guerra infinita, Feltrineli, Milano, 2002, cap. vi; C. Bonini, Guantanamo. Usa, viaggio nella prigione del terrore, Einaudi, Torino, 2004, que contiene en apéndice las ordenanzas y reglamentos que han autorizado estos horrores; Amnesty Internatinal, $A b u$ Ghraib e dintorni. Un anno di denunce inascoltate, Ega editore, Torino, 2004.

${ }^{4}$ Recuérdense las tesis de Alan Dershowitz, Why Terrorism Works. Understanding the Threat Responding to the Challenge (2002), trad. Italiana: Terrorismo, Carocci, Roma, 2003, pp. 118 y ss. y 125 y ss.

${ }^{5}$ Sobre este modelo puede verse S. SEnESE, "La trasformazione delle strutture giuridiche in America Latina”, en Il Mulino, n² 246, julio-agosto de 1976, pp. 529-553.
} 
como no-persona, que no merece la aplicación de las garantías ordinarias del correcto proceso ni las previstas para los prisioneros por el derecho humanitario de guerra. Naturalmente, las torturas no aparecen llamadas por su nombre. Se las califica de "abusos", para no admitir oficialmente el crimen.

El acta de nacimiento del derecho penal del enemigo está en la legitimación política de estas prácticas punitivas. En la base de la identificación del terrorista y del criminal como enemigos subyacente a las mismas, hay un deslizamiento semántico en función de autolegitimación; la confusión entre derecho penal y guerra: nada más destructivo del derecho y del estado de derecho. Esta confusión ha producido una suerte de perversa legitimación cruzada: de la guerra, rehabilitada como instrumento penal de mantenimiento del orden público internacional; del derecho penal del enemigo, a su vez legitimado en sus formas terroristas con la lógica de la guerra.

Esta deformación del significado de las palabras y del sentido común se ha producido sobre todo en la interpretación de los estragos del 11 de septiembre. ¿Fueron éstos un acto de "guerra" o un acto de "terrorismo"? ¿Se trató de una agresión bélica, o no fueron más bien un crimen, un crimen contra la humanidad, que es como siempre se ha calificado a los actos terroristas? Pues las guerras las hacen los estados, suponen confines y territorios, ejércitos regulares y enemigos ciertos y reconocibles. Los ataques terroristas, por el contrario, pertenecen al género de las emboscadas perpetradas por organizaciones ramificadas y clandestinas.

Es claro que la identificación de aquel acto terrorista como un acto de guerra y no como un crimen elimina la distinción y la asimetría entre derecho y guerra. Hablaré más adelante de los desastrosos efectos de esta confusión a los fines de la lucha contra el terrorismo; lucha que, precisamente, tiene su específica fuente de legitimación en la asimetría entre derecho y guerra, de la que obtiene también su específica capacidad de aislamiento y desarme político del terrorismo. Pero quiero señalar de inmediato los efectos de relegitimación de la guerra como modo de lucha contra el terrorismo y, paradójicamente, del propio terrorismo como guerra, provocados por esta deformación del lenguaje de la política y del derecho. Gracias a esta simplificación maniquea de la política y del lenguaje de la política, bajo la enseña de la dicotomía amigo/enemigo, no sólo la guerra, sino también las violencias ejercidas por los vencedores en los territorios ocupados han sido llamadas "lucha al terrorismo"; mientras todo lo que 
contrasta con los métodos de esta lucha ha sido etiquetado y descalificado como "terrorismo" y como alianza o connivencia con el terrorismo, a su vez acreditado como "guerra".

Es una distorsión del lenguaje que constituye el síntoma amenazante de un posible totalitarismo internacional justificado por una suerte de estado de sitio global y permanente. En efecto, parece que en el momento en que los fenómenos que hemos de entender y afrontar adquieren mayor complejidad, nuestro lenguaje y nuestras categorias, en vez de hacerse a la vez más complejas y diferenciadas, se simplifican y se confunden, hasta su extrema simplificación en la oposición elemental del "Bien" contra el "Mal": ayer el comunismo, hoy el terrorismo. Por lo demás, la simplificación ha operado siempre como factor de autolegitimación a través de la figura del enemigo: del enemigo exterior, para legitimar la guerra externa, preventiva y virtualmente permanente, y del enemigo interno, sospechoso de connivencias con aquél, modo de legitimar medidas de emergencia y restrictivas de las libertades fundamentales de todos.

Es el esquema schmittiano de la oposición amigo/enemigo, que se ha impuesto sobre todo en los Estados Unidos. Un esquema, sin embargo, que no es precisamente, como pretendía Schmitt, el paradigma de la política, sino el de la guerra, que es la negación de toda política racional, tanto en las relaciones internacionales como en las internas, donde no por casualidad acaba por secundar, en nombre de la emergencia, la disolución del estado de derecho, basada en la difusión del miedo y en la demanda de lealtades y de consenso apriorístico a cualquier arbitrio y abuso. Con la agravante de que la fórmula no sólo expresa la concepción y el tratamiento del criminal como enemigo, sino también la del enemigo como criminal, privado, en consecuencia, al mismo tiempo, tanto de las garantías procesales del imputado como de las previstas para los prisioneros de guerra por las convenciones de Ginebra. Dicho sencillamente, expresa la criminalización del enemigo y la militarización de la justicia.

En esta exclusión de los "enemigos combatientes" del derecho -tanto interno como internacional- se manifiesta, en fin, la valencia racista de la fórmula del derecho penal del enemigo tal y como se ha expresado en las leyes americanas y en los horrores de Guantánamo y de Abu Ghraib. La etiqueta "terrorismo", como sinónimo de pulsión homicida irracional, sirve para caracterizar al enemigo como no-humano, no-persona, que no merece ser tratado con los instrumentos del derecho ni con los de la política. Es el vehículo de una nueva antropología de la desigualdad, marcada 
por el carácter tipológicamente criminal, demencial e inhumano, asociado al enemigo, y, de este modo, también de una nueva y radical asimetría entre "nosotros" y "ellos".

\section{El PARADIGMA DEL ENEMIGO Y LA DISOLUCIÓN DEL DERECHO PENAL (DERECHO PENAL Y GUERRA)}

Llego así al segundo significado de la fórmula "derecho penal del enemigo", el de su uso en sentido normativo como nuevo modelo o paradigma del derecho penal. ¿Por qué el "derecho penal del enemigo", en el segundo de los significados aludidos, es una contradicción en los términos, que contradice y, por tanto, niega la idea misma del derecho penal?

Por múltiples razones, todas conectadas con el hecho de que el derecho penal, más bien el derecho tout court, es la negación del enemigo; porque es el instrumento, el medio por el que las relaciones de convivencia pasan del estado salvaje al estado civil y cada uno es reconocido como persona. En este sentido, la pena es la negación de la venganza, del mismo modo que el derecho en general es la negación de la guerra. Recuérdese el paradigma hobbesiano: el derecho es la alternativa al bellum omnium, es decir, a la violencia desregulada de la guerra. Con él se sale del estado de naturaleza y la sociedad salvaje se civiliza, de manera que en la sociedad civil instituida por el derecho ya no existen enemigos sino asociados, no guerras sino penas y delitos. Como afirma Hobbes: "un daño infligido a quien es enemigo declarado no puede calificarse de castigo" sino que habrá de ser considerado como "acto de hostilidad". ${ }^{6}$ Por lo demás, este reconocimiento de la antinomia entre derecho y guerra, entre pena y venganza se remonta a los orígenes de la civilidad jurídica, cuando el nacimiento del derecho penal fue representado en la mitología griega con la institución del areópago por Atenea, que puso fin al ciclo de la venganza de la sangre. ${ }^{7}$

Si esto es cierto, el esquema bélico del derecho penal del enemigo contradice radicalmente la idea misma del derecho penal en todos sus elementos y momentos; primeramente, en el modo de concebir el tipo penal, y, luego, en la concepción del juicio.

\footnotetext{
${ }^{6}$ Leviatán, trad. de C. Mellizo, Alianza Editorial, Madrid, 1989, p. 251.

${ }^{7}$ Es el momento del tránsito de la justicia privada a la justicia de la ciudad, celebrado en las Euménides de Esquilo, e históricamente documentado en la ley de Dracón del año 620 a. C. Al respecto, remito a mi Derecho y razón. Teoría del garantismo penal, trad. española de P. Andrés lbáñez, J. C. Bayón, R. Cantarero, A. Ruiz Miguel y J. Terradillos, Trotta, Madrid, 7ª ed., 2005, pp. 333-334.
} 
La primera deformación concierne al principio de legalidad en la determinación de lo punible, que aquí ya no es el delito sino el reo, con independencia del delito. La sustancia del principio de legalidad está en la previsión legal como punibles de "tipos de acción" y no de "tipos de autor"; en castigar "por lo que se hace" y no por "lo que se es"; en identificar las conductas dañosas y no, también, a los sujetos dañosos, más bien tutelados por ese principio en sus diversas y específicas identidades, aunque sean desviadas; en dirigir el juicio a la prueba de los hechos y no la inquisición sobre las personas.

El derecho penal del enemigo invierte este esquema. En él la predeterminación legal y la averiguación judicial del hecho punible ceden el puesto a la identificación del enemigo, que inevitablemente, al no estar mediada por la prueba de actos específicos de enemistad, se resuelve en la identificación, la captura y la condena de los sospechosos. En efecto, el enemigo debe ser castigado por lo que es y no por lo que hace. El presupuesto de la pena no es la realización de un delito, sino una cualidad personal determinada en cada ocasión con criterios puramente potestativos como los de "sospechoso" o "peligroso". Ni sirven pruebas sino diagnosis y prognosis políticas. Y es claro que el esquema puede ampliarse en múltiples direcciones: hacia los pedófilos, los mafiosos, las diversas categorías de marginados sociales; todo invariablemente según la concepción del delincuente político como "enemigo" a suprimir por el interés general, a partir de su identificación extra legem según criterios sustancialistas y por procedimientos inquisitivos. Conforme a este modelo, lo que cuenta es la eficiencia, junto con la idea fácil, propia del sentido común autoritario, de que la justicia debe mirar al reo por detrás del delito, a su peligrosidad detrás de su responsabilidad, a la identidad del enemigo más que a la prueba de sus actos hostiles.

La consecuencia es una segunda deformación que trastoca la naturaleza del juicio penal. En efecto, esta mutación sustancialista y subjetivista del modelo de legalidad bajo la enseña del enemigo produce como resultado la quiebra de todas las garantías procesales. Si el delincuente y el imputado son enemigos, el juez a su vez se convierte en "enemigo del reo", según las palabras de Beccaria, ${ }^{8}$ y pierde inevitablemente toda su imparcialidad. El esquema del amigo/enemigo opera aquí en dos direcciones, en la del sujeto y en la del objeto del juicio.

$\overline{{ }^{8} \text { De los delitos y }}$ de las penas, trad. de J. A. de las Casas, Alianza Editorial, Madrid, 1968, p. 59. 
En primer lugar, imprime una connotación partisana tanto a la acusación como al juicio, transformando el proceso en momento de "lucha" contra la criminalidad terrorista o de cualquier modo organizada. El proceso no es el que Beccaria llamaba "informativo, esto es, la indagación indiferente del hecho" donde el juez es "un indiferente indagador de la verdad", sino que se convierte en "un proceso ofensivo" en el que "el juez se hace enemigo del reo, de un hombre encadenado..., [y] no busca la verdad del hecho, busca sólo el delito en el encarcelado. Le pone lazos y se cree desairado si no sale con su intento en perjuicio de aquella infalibilidad que el hombre se atribuye en todos sus pensamientos".

En segundo lugar, el esquema se manifiesta en la alteración del objeto procesal, que se sigue directamente de la que afecta a los tipos penales. Si el presupuesto de la pena está representado por la sustancial personalidad terrorista o mafiosa del autor, más que por hechos delictivos determinados, el proceso deja de ser un procedimiento de verificación empírica de las hipótesis de acusación para degradarse a técnica de inquisición sobre la persona, es decir, sobre la subjetividad sustancialmente enemiga o amiga tal como se expresa no tanto en delitos cometidos por aquél como en su identidad política o religiosa, en su condición social o cultural, en su ambiente y en su trayectoria vital. En suma, en coherencia con la nueva estructura del proceso como lucha, objeto del juicio no es tanto y sólo si el acusado ha cometido un hecho terrorista o en cualquier caso criminal, sino si él ha sido y si es todavía un terrorista o un connivente con el terrorismo.

\section{LA ineficaCia del dereCho Penal del enemigo (medios y fines Penales)}

Llegados a este punto, hay que preguntarse si el nuevo paradigma es siquiera eficaz en la lucha contra el terrorismo. Pues bien, lo que voy a sostener es que el derecho penal, o, mejor, la represión salvaje y desregulada cubierta bajo el noble título de derecho penal, pierde no sólo su legitimidad, sino también su eficacia. Porque pierde su asimetría con el crimen.

Volvamos a la cuestión del lenguaje. ¿Por qué la fundamental importancia de la cuestión de si los atentados del 11 de septiembre eran un crimen o un acto de guerra? ¿Por qué es tan importante que el terrorismo sea considerado fenómeno criminal y no fenómeno bélico? Porque las

${ }_{9}^{9}$ Op. cit., pp. 58-59. 
respuestas que nuestra civilidad jurídica ha previsto y reclama para cada uno de ambos fenómenos son, no sólo diversas, sino opuestas. Para repeler o neutralizar un acto de guerra, se responde con la guerra de defensa o con la movilización general contra el Estado agresor. A un crimen, aunque sea gravísimo, se responde con el derecho penal, es decir, con la punición de los culpables, que puede ser muy severa; por tanto, no con ejércitos y bombardeos, sino con la policía y, por consiguiente, con el esfuerzo y la capacidad investigadora dirigidos a establecer las responsabilidades y a neutralizar la compleja red de las complicidades que les diera y siga dándoles soporte.

Es claro que los atentados del 11 de septiembre de 2001 no fueron un acto de guerra, puesto que ésta, según la clásica definición de Alberico Gentili, consiste en una "publicorum armorum contentio", ${ }^{10}$ es decir, en un conflicto entre estados, y, precisamente, entre ejércitos públicos, es decir, entre fuerzas estatales reconocibles como públicas. Mientras el terrorismo consiste en una violencia dirigida a sembrar terror entre víctimas inocentes, por obra, no ciertamente de una fuerza "pública", sino de organizaciones ocultas, que actúan clandestinamente y están escondidas desde el principio, como hacen siempre los criminales. A esos terribles estragos se ha respondido con la guerra, precisamente porque fueron calificados como actos no solo terroristas sino de "guerra". Y la guerra ha golpeado, como está en su lógica, a decenas de millares de víctimas inocentes, desencadenando ulteriores odios, violencias y fanatismos.

Entonces, es preciso preguntarse si la respuesta de la guerra, presentada como un signo de firmeza, no ha sido realmente otra cosa que un signo de debilidad, y un acto de abdicación de la razón más que del derecho. Si no es, precisamente, la guerra, y con ella la espiral incontenible de la violencia y la derrota del derecho y de la razón, lo que perseguían los terroristas como su principal objetivo estratégico. Si, al contrario, responder con el derecho y no con la guerra, no habría sido el modo idóneo de lograr la máxima eficacia y valor simbólico a los fines del aislamiento y la derrota del terrorismo.

En efecto, es evidente que el terrorismo internacional, al consistir en una red de organizaciones clandestinas ramificadas en decenas de países, puede ser afrontado y batido sólo con una red de fuerzas policiales, es decir, con operaciones de policía dirigidas a identificar a los jefes, las

${ }^{10}$ A. Gentili, De iure belli libri tres (1588), lib. 1, cap. 1, ed. de J. Brown Scott, Clarendon Press, Oxford, 1933, p. 12. 
estructuras, los financiamientos y las complicidades. Ciertamente, tras los atentados del 11 de septiembre y gracias a la general solidaridad entonces manifestada con los Estados Unidos, habría sido posible una movilización de las policías y de los servicios secretos de medio mundo para capturar a los culpables e identificar las redes de sus acólitos. Sin el clamor y la espectacularidad de la guerra, sino con los métodos mucho más eficaces del secreto, la coordinación de las investigaciones, la identificación de las organizaciones terroristas, y, obviamente, un empleo de la fuerza dirigido a desarmar a sus componentes y entregarlos a la justicia. Con ello se habría acrecentado a escala mundial la credibilidad de Occidente y de los propios Estados Unidos. Y, sobre estas bases, quizá también hubiera sido posible favorecer la caída pacífica del régimen talibán, que se nutría sobre todo de las ayudas económicas y militares de Pakistán, e incluso del régimen de Sadam Hussein. De haber prevalecido la paciencia y la razón, seguramente, hoy el terrorismo estaría bastante más aislado y sería más vulnerable.

En cambio, la guerra, con sus inútiles devastaciones -incluidas las redadas indiscriminadas, las torturas, los secuestros, en definitiva, todo lo que es propio del derecho penal del enemigo- sólo puede agravar, como gasolina en el fuego, los problemas que pretende resolver. Puede satisfacer la sed de venganza, pero en perjuicio de las víctimas inocentes. Puede galvanizar y movilizar a las opiniones públicas y ofrecer así un contingente apoyo a las políticas de excepción de los gobiernos. Pero ciertamente no sirve para golpear a las organizaciones terroristas, sino que, por el contrario, tiene el efecto de reforzarlas alimentando el caldo de cultivo del fanatismo. En efecto, la provocación de la guerra, es, precisamente, el objetivo de todo terrorismo, dado que él mismo se propone, simétricamente, como guerra y como tal quiere ser reconocido.

Por eso, la respuesta al terrorismo será tanto más eficaz cuanto más asimétrica resulte. Y para ello hace falta que no se lo eleve a la categoría de Estado beligerante y que sus agresiones sean reconocidas como crímenes y no como actos de guerra; que no se le dé respuesta con la lógica primitiva de la guerra y del derecho penal del enemigo, perfectamente simétrica a la del terrorismo, pues también se opone a la lógica del derecho y se proyecta inevitablemente sobre personas inocentes. Pues, siendo cierto que el terrorismo es un fenómeno político, debe ser entendido y afrontado también, y sobre todo, políticamente. Pero es justo en la asimetría respecto a él convencionalmente establecida por su calificación jurídica como "crimen" donde reside el secreto de su pérdida de fuerza y de su aislamiento y por 
ello el papel del derecho penal como factor de paz y de civilización, es decir, instrumento del tránsito del estado de guerra al estado de derecho, de la sociedad salvaje a la sociedad civil. Pues, en fin, el terrorismo es, en todo caso, al igual que la piratería, violencia privada, aunque sea trasnacional, y no violencia pública, como lo son en cambio la pena y la intervención de la policía.

Menos aún la guerra y la lógica del amigo/enemigo pueden ser un instrumento de mantenimiento del orden internacional, al modo que aparece concebido en los documentos estratégicos de la administración del presidente George W. Bush. ${ }^{11}$ No es casual que la guerra preventiva al terrorismo se conciba en esos documentos como "infinita". Pues, de modo diverso a lo que sucede con las guerras en sentido propio, que se concluyen siempre con la derrota de uno de los estados contendientes y por ello con la paz, una guerra preventiva de una violencia privada, como es, precisamente, el terrorismo, es de manera inevitable permanente, y su declaración equivale a proyectar una regresión planetaria de las relaciones internacionales al bellum omnium, es decir, a la guerra infınita propia del estado precivil y salvaje: cuando en el ciclo de la violencia todavía no se había interpuesto la intervención asimétrica del derecho como instrumento de civilización de los conflictos, mediante la proscripción como delitos de la venganza y la represalia.

Terrorismo y guerra, en efecto, se alimentan recíprocamente. Ni la guerra podrá nunca derrotar al terrorismo, ni el terrorismo podrá jamás derrotar a la guerra. Si acaso, tienden a asemejarse el uno a la otra como violencias indiscriminadas que golpean y aterrorizan a los inocentes. Solamente la intervención del derecho puede interrumpir la espiral. En efecto, las violencias terroristas - los estragos, asesinatos, secuestros, decapitaciones de inocentes- son identificables y reconocibles como crímenes y como tales políticamente degradables y jurídicamente deslegitimables, si los estados reaccionan frente a ellos con los instrumentos del derecho, es

\footnotetext{
${ }^{11}$ En el Project for a New Americam Century, elaborado en 1998 por los principales colaboradores de George W. Bush antes de su elección, se afirma que los Estados Unidos no deberán tolerar nunca potencias industriales o militares concurrentes en la escena internacional. Este proyecto imperial ha sido obsesivamente reafirmado, con tonos de cruzada, en todas las intervenciones públicas del presidente Bush posteriores al 11 de septiembre, en particular en el discurso del 14 de septiembre de 2001 en el que fue declarada la guerra infinita para "liberar al mundo del mal", y en la declaración de la guerra preventiva "de duración indefinible" contenida en el documento estratégico del 17 de septiembre de 2001. Los documentos en los que se expone esta nueva doctrina pueden verse en: Varios Autores, De Bush a Bush. La nuova dottrina stratégica attraverso i documenti ufficiali (1991-2003), La Città del Sole; G. Mammarella, Liberali e conservatori. L'America da Nixon a Bush, Laterza, Roma-Bari, 2004.
} 
decir, con la determinación de las responsabilidades según las garantías del correcto proceso, y con la aplicación de las penas previstas en la ley. Es en esta asimetría, precisamente asegurada por las formas jurídicas, donde reside, repito, la diferencia, más aún la antinomia y la contraposición, no sólo entre derecho y guerra, sino también entre derecho y terrorismo, y la capacidad de descalificación y neutralización del segundo por obra del primero. $\mathrm{Y}$ es en la atenuación de esta asimetría entre Estado y terrorismo, entre la reacción legal a la violencia criminal y la criminalidad misma, donde radica la causa profunda del fracaso de la guerra "preventiva" y del derecho penal del enemigo.

La respuesta de la guerra ilegal y de la represión salvaje, a su vez ambas terroristas, al anular la asimetría entre instituciones públicas y organizaciones terroristas, ha privado a las primeras de su mayor fuerza política, degradándolas al nivel de las segundas o, lo que es lo mismo, elevando a las segundas al nivel de las primeras como estados enemigos y beligerantes. Es prueba de ello el hecho de que el terrorismo no haya sido debelado por la guerra en Afganistán ni por la emprendida contra Irak, en el curso de las cuales han sobrevivido sus principales jefes y responsables, empezando por Osama Bin Laden. Por el contrario, ha consolidado las bases de consenso y la capacidad de reclutamiento del terrorismo, incrementando la inseguridad y al mismo tiempo el antiamericanismo en todo el mundo.

Es así como la ilicitud de la guerra y del derecho penal del enemigo se ha confirmado como el reflejo de su inidoneidad como "medio" respecto de cualquier fin presentado como su "justa causa". Esta irracional incongruencia no es casual. Es la trágica confirmación del nexo indisoluble que liga derecho y razón, legalidad y seguridad, medios y fines, formas y sustancia de los instrumentos, incluso coercitivos, de tutela de los débiles frente a la ley del más fuerte.

\section{v. Fundamentalismo occidental \\ (LA ALTERNATIVA DEL DERECHO Y DE LA RAZÓN)}

En la base de esta pérdida de la razón en la respuesta al terrorismo hay una regresión ideal y cultural de las sociedades occidentales, alimentada por el miedo al diverso y a la vez interpretada y secundada, como fácil base del consenso, por los gobiernos, por la mayoría de las fuerzas políticas y de los medios de comunicación. Gran parte de la opinión pública de los países ricos vive la globalización y sus efectos -las inmigraciones clan- 
destinas masivas, la competencia de las producciones de los países pobres, el empobrecimiento de las clases medias y marginales y el espectáculo mismo de la miseria, el hambre y las enfermedades de los que es víctima gran parte de la población mundial- como un atentado y una amenaza permanente a la propia seguridad, a la propia identidad, a los propios niveles de bienestar.

De aquí el desarrollo, tanto en los Estados Unidos como en Europa, de movimientos racistas y xenófobos, que han redescubierto una antropología de la desigualdad fundada sobre la objetivación de las culturas y de las comunidades locales como entidades naturales, orgánicas, unitarias y monolíticas, y sobre la demonización de las culturas extranjeras y diversas. De aquí también la opción por la violencia y por la exclusión, bajo la enseña de la oposición amigo/enemigo, y consecuentemente por la demolición de las libertades fundamentales mismas como precio necesario de una ilusoria seguridad. Es el imperio del miedo, construido en los Estados Unidos, según la hipótesis de Benjamin Barber, ${ }^{12}$ que podría expandirse a escala global.

Es en este terreno, más que en ningún otro, donde se mide la tendencial degeneración fundamentalista de las democracias occidentales, debida a su incapacidad de pacífica convivencia con el resto del mundo. Una degeneración que contradice la laicidad de las instituciones y cuyo síntoma más elocuente es el paradigma del enemigo. La guerra actual, como se ha visto, ha asumido connotaciones terroristas, configurándose cada vez más abiertamente como exterminio de masas que golpea sobre todo a las poblaciones inermes. Su inmoralidad y su ilegalidad son por ello tan radicales que en estos años han podido ser relanzadas, tras su solemne repudio como "flagelo" en la Carta de la onU y de muchas constituciones nacionales, solamente para derrotar al enemigo como mal absoluto en nombre de una moral a su vez absoluta, signo de un nuevo fundamentalismo, opuesto pero simétrico al que anima al terrorismo. Bajo este aspecto, la impresión es que se está asistiendo a un retorno a las viejas guerras de religión. No

\footnotetext{
${ }^{12}$ B. R. Barber, Ferar's Empire. War, Terorism an Democracy (2003), trad. italiana, L'impero della paura. Potenza e impotenza dell'America nel nuovo millennio, Einaudi, Torino, 2004. Véase también R. Falk, L'eclisse dei diritti umani, en L. Bimbi (Ed.), Not in my name. Guerra e diritto, Editori Riuniti, Roma, 2003, pp. 72-86. (Hay trad. española: No en mi nombre. Guerra y derecho, Trotta, Madrid, 2003.) Sobre el papel de la desinformación y de las falsificaciones, promovidas por los aparatos de los servicios secretos y amplificadas por los media, en la construcción del miedo por el terrorismo, véase el documentado estudio de C. Bonini y G. D’Avanzo, Il mercato della paura. La guerra al terrorismo islamico nel grande inganno italiano, Einaudi, Torino, 2006.
} 
es casual que a esta visión maniquea -el choque de civilizaciones del que ha hablado Samuel Huntington- contribuya la contraposición al fundamentalismo islámico de la religión cristiana -relanzada en estos años como factor de la identidad occidental- y no los principios del laicismo y la tolerancia.

De aquí las reiteradas apelaciones a Dios de los "teo-cons" americanos y los insostenibles oxímorons con los que ha sido re-exhumada y rebautizada la antigua categoría de la guerra justa, ahora "guerra ética", "humanitaria", "en defensa de los derechos humanos", como en Kosovo, o de la "seguridad internacional", de la democracia y hasta de la paz, como en Irak. Por otra parte, a la autoidentificación con el Bien en la lucha contra el Mal se asocian otros dos rasgos característicos del fundamentalismo: la idea ético-cognoscitiva según la cual el Bien es también la Verdad, que por eso no tolera dudas y disensos, y a la vez el principio de que el fin justifica los medios, incluida paradójicamente la mentira, como ha sucedido con la falsa acusación de colusión con el terrorismo y posesión de armas de destrucción masiva, dirigida contra el régimen iraquí, en apoyo de la última guerra. Es, pues, evidente que las apelaciones ético-religiosas a los valores de Occidente y a la lucha del Bien contra el Mal sirven eficazmente para cubrir los verdaderos intereses en juego: los de una economía depredadora y, por otra parte, de un poder militar y político que no toleran reglas, límites ni controles.

Naturalmente, la pretensión de encarnar el bien y la verdad contra el mal tiene por efecto la incomprensión de la realidad del terrorismo, obstaculizada por una representación simplificada y maniquea del mismo. Expresiones genéricas como "terrorismo", "yihad islámica mundial" han asumido en el lenguaje político significados indeterminados, idóneos para agregar las formas más diversas de fanatismo, originadas en contextos y momentos diversos -religiosos, nacionalistas o simplemente políticos- y al mismo tiempo cualquier forma de resistencia y de oposición. Pero, precisamente, esta imprecisión del lenguaje, que une fenómenos heterogéneos bajo una misma etiqueta genera el riesgo de favorecer la alianza entre los diversos terrorismos y al mismo tiempo impedir, con la simplificación maniquea, cualquier conocimiento del fenómeno que se pretende combatir. Todo el mundo árabe o al menos sus manifestaciones políticas de rechazo a Occidente resultan así identificadas con el Islam, asumido al mismo tiempo como el caldo de cultivo del terrorismo. A su vez el fenómeno terrorista aparece representado como una entidad unitaria -al-Quaeda, con un úni- 
co jefe, Osama Bin Laden- detrás de la cual estaría en cada ocasión un Estado diverso a agredir y destruir: ayer Afganistán, después Irak, mañana Irán. Obviamente estas imágenes no tienen nada que ver con la realidad. El terrorismo islámico está formado por grupos diversos y dispares, difundidos de distintas maneras en Irak, Chechenia, Egipto, Indonesia y Europa; a veces relacionados entre sí, pero cada uno con su historia, identidad y motivaciones diferentes, que sólo los bombardeos y los carros armados, y por otra parte, la pobreza y la ignorancia, pueden hacer confluir bajo la enseña de un odio generalizado a Occidente. Se trata de un fenómeno que debería ser afrontado, no con la guerra, sino, a corto plazo, con investigaciones policiales diferenciadas, y promoviendo el desarrollo económico y cultural, a largo plazo.

En suma, si el fin del terrorismo es la guerra y sus armas son el miedo, el chantaje a las democracias y el ofuscamiento de sus principios y valores, hay que reconocer que es lo que se está realizando, gracias a la respuesta americana de la guerra, a la exclusión de la onv, las torturas y la represión salvaje informadas en la idea del enemigo. La estrategia militar de los Estados Unidos en la lucha contra el terrorismo se ha revelado trágicamente fallida. Dos guerras con otros tantos estados, cuando las organizaciones terroristas consisten en variadas redes clandestinas compuestas de individuos sin rostro, han tenido el único efecto de secundar al terrorismo, degradar nuestras democracias, acrecentar la inseguridad y reducir las libertades civiles.

Hay más: gracias a esta confusión entre guerra y punición, se está produciendo una regresión al estado de naturaleza de la entera convivencia internacional. Ya que las nuevas guerras son "preventivas" y a la vez "infinitas", en el sentido de que son castigos ejemplares infligidos a aquellos estados a los que en cada ocasión se etiqueta de "estados canallas". Cumplen la misma función del uso terrorista del derecho penal en un ordenamiento despótico. El instrumento es la fuerza de las armas en función represiva, además de preventiva. El mensaje es la falta de límites y de rémoras. El criterio no sólo es el mantenimiento del orden global sino la venganza - dos guerras, en Afganistán y en Irak, tras los atentados de las Twin Towers - en el sentido primitivo de venganza de la sangre que golpea al grupo contrario, incluido el inocente.

Frente a estos procesos, el cometido de la cultura jurídica y de la jurisdicción es restablecer la radical asimetría entre derecho y crimen, instituciones y terrorismo, imputados y enemigos. En efecto, la razón jurídica 
del estado de derecho no conoce enemigos y amigos, sino sólo culpables e inocentes. No admite excepciones a las reglas sino como hecho extra- o anti-jurídico, dado que las reglas -si se toman en serio como reglas, y no como simples técnicas- no pueden plegarse a conveniencia según la ocasión. Y en la jurisdicción el fin no justifica nunca los medios, dado que los medios, o sea las reglas y las formas, son las garantías de verdad y libertad, y como tales tienen valor para los momentos difíciles tanto más que para los fáciles; mientras el fin no es el éxito sobre el enemigo en todo caso, sino la verdad procesal obtenida sólo en el respeto de aquéllas y que padece gravemente cuando se las quebranta. Contraponer al desafío del terrorismo la alternativa del derecho y de la razón es esencial para salvaguardar no sólo los principios de garantía del correcto proceso sino también el futuro de la democracia.

Volver al Índice >> 